\title{
Dificuldade de Adequação às Medidas Técnicas: a percepção das empresas exportadoras de alimentos
}

\author{
Rosane Nunes de Faria ${ }^{1}$ \\ Heloísa Lee Burnquist ${ }^{2}$ \\ Maria Helena de Aguiar Pereira e Pestana ${ }^{3}$
}

Resumo: Este artigo mensura o grau de dificuldade de adequação às medidas técnicas para as empresas exportadoras de alimentos no Brasil, por meio da construção de índices. Foi aplicado um questionário estruturado a 117 empresas e os dados foram analisados por meio de técnicas estatísticas multivariadas. As variáveis detalhadas no trabalho, que representam tipos de medidas técnicas usualmente requeridas para a exportação de alimentos, foram agrupadas em dois índices: o Îndice de Especificação Técnica (IET) e o Índice de Requerimento de Informação (IRI). O teste de Wilcoxon mostrou que as empresas têm maior dificuldade de adequação às especificações técnicas como exigências no processo de produção, testes de conformidade, segurança do alimento, características do produto e requisitos de meio ambiente.

Palavras-chave: medidas técnicas, exportações de alimentos, índices.

Abstract: This article measures the degree of difficulty of compliance to technical measures for firms that export food in Brazil, through the construction of indexes. It has conducted a survey of 117 firms and data collected were analyzed by multivariate analysis. The detailed variables in the article which represent types of technical measures usually required in food export were grouped into two indices: Technical Specification Index (TSI) and Requirements Information Index (RII). The Wilcoxon test revealed that firms have greater difficulty to comply products and processes with technical specifications such as plant and production process requirements, conformity

1 Professora Doutora do curso de Ciências Econômicas da Universidade Federal de São Carlos - Campus Sorocaba. E-mail: rnfaria@ufscar.br

2 Professora Doutora da Esalq/USP. E-mail: hlburnqu@esalq.usp.br

3 Professora Auxiliar do Instituto Superior de Ciências do Trabalho e da Empresa (ISCTE) Lisboa - Portugal. E-mail: gageiropestana@gmail.com 
630 - Dificuldade de Adequação às Medidas Técnicas:

a percepção das empresas exportadoras de alimentos

assessment procedures, food safety, product's characteristics and environmental requirements.

Key-words: technical measures, food products export, indexes.

Classificação JEL: F13; F14.

\section{Introdução}

O comércio de alimentos, assim como o de outros produtos, é regulado por uma variedade de normas e regulamentos técnicos que se diferenciam de país para país. Muitas dessas diferenças refletem apropriadamente a diversidade nas condições de demanda por normas e regulamentos técnicos que se modificam de acordo com a cultura, os gostos, os hábitos e o nível de renda de cada país. No entanto, muitas medidas técnicas ${ }^{4}$ podem ser estabelecidas com o objetivo de proteger os produtores domésticos. Neste caso, as diferenças podem ser propositais e podem impor restrições ao comércio além do necessário para atingir os objetivos de saúde, segurança, qualidade etc.

De acordo com Josling, Roberts e Orden (2004) as medidas técnicas são particularmente importantes no comércio de produtos agrícolas primários e processados e se tornarão mais complexas nos próximos anos como resultado do aumento da renda dos países e, consequentemente, da crescente preocupação dos consumidores em relação a aspectos que envolvem a qualidade do produto, questões ambientais e de segurança do alimento.

A literatura nacional sobre os impactos das medidas técnicas nas exportações ainda é escassa, mas alguns trabalhos já identificam efeitos dessas medidas nas exportações de produtos agroalimentares no Brasil. Para a exportação de carne bovina, Miranda (2001) identificou impacto nos preços de exportação devido a um embargo europeu às exportações de carne brasileira. Ainda para a carne bovina, Junqueira (2006) identificou reduções da quantidade importada pelos Estados Unidos e União Européia decorrentes de embargos provenientes do aparecimento de febre aftosa ou suspeita de território contaminado pelo "Mal da Vaca Louca". Faria (2004) encontrou efeito positivo da retirada de uma medida fitossanitária nas exportações de mamão da variedade Golden para os Estados Unidos. Souza e Burnquist (2007) simularam o impacto de um banimento total das exportações de melão para a União Européia, com redução de 2,2\% no preço doméstico do produto.

4 O termo medidas técnicas, neste artigo, engloba tanto os regulamentos quanto as normas técnicas. 
Um dos potenciais efeitos econômicos das medidas técnicas é o aumento dos custos de adequação dos exportadores aos requisitos impostos pelo país ou cliente comprador. As medidas técnicas podem induzir a necessidade de adequar o design de um produto, reorganizar o sistema de produção, realizar testes múltiplos e certificações, o que pode onerar a exportação e até mesmo torná-la inviável para algumas empresas.

Nesse sentido, este artigo analisa a dificuldade que as empresas brasileiras exportadoras de alimentos enfrentam para adequar seus produtos e processos às medidas técnicas dos países compradores. O objetivo é mensurar o grau de dificuldade de adequação por meio da construção de índices específicos e, assim, identificar os tipos de medidas técnicas que as empresas possuem mais dificuldade para se adequar.

Índices de restritividade das exigências técnicas às exportações brasileiras também foram calculados por Faria e Burnquist (2006). As autoras argumentam que o acompanhamento da evolução desses índices ao longo do tempo proporcionaria um instrumento para os formuladores de política no sentido de discernir onde devem ser concentrados esforços para amenizar os efeitos das medidas técnicas ao comércio.

Neste sentido, a contribuição do presente artigo é fornecer informações específicas para a indústria de alimentos, visto que Faria e Burnquist (2006) não analisaram atividades econômicas separadamente, além de disponibilizar essas informações para serem utilizadas em trabalhos futuros.

\section{Fundamentação teórica}

\subsection{As medidas técnicas no comércio internacional de alimentos}

De acordo com Roberts, Orden e Josling (1999), as exigências técnicas podem ser definidas como regulamentos e normas técnicas que governam a venda do produto dentro do mercado nacional e têm como objetivo principal a correção de ineficiências de mercado advindas de externalidades associadas à produção, à distribuição e ao consumo desses produtos.

A principal razão para a introdução de medidas técnicas é a correção de falhas de mercado que podem surgir na presença de externalidades, assimetria de informação, custos de transação e bens públicos. Nestas situações de ineficiências do mercado, o estabelecimento de normas e regulamentos pode aumentar o bem-estar da sociedade e torna-se justificável ainda que isso crie impactos indesejáveis no comércio e nas forças competitivas do mercado (ORGANIZAÇÃO MUNDIAL DO COMÉRCIO, 2005). 
Para o caso específico de alimentos, Josling, Roberts e Orden (2004) apresentam uma classificação das medidas técnicas em três categorias: proibição de importação, especificações técnicas e requerimentos de informação.

A proibição de importação constitui na categoria de medidas técnicas mais restritivas e é comumente adotada quando não existem medidas alternativas factíveis para reduzir os riscos biológicos ou toxicológicos associados, por exemplo, a pestes ou substâncias que podem causar danos à agricultura, às espécies nativas da flora e fauna de um país. Essa medida pode variar desde a proibição total ou parcial, a até mesmo exigências de períodos de quarentena ou proibições sazonais.

As especificações técnicas são medidas que estipulam as condições técnicas que os exportadores precisam se adequar para entrar no mercado do país importador. Em princípio, qualquer empresa que esteja disposta a arcar com os custos para a adequação às especificações técnicas poderia comercializar seus produtos para o país importador. Porém, na prática, muitas empresas são impossibilitadas de exportarem tanto por restrições internas, como altos custos de adequação, quanto por restrições externas, como infraestrutura do país inadequada em termos de serviços públicos e privados de laboratórios de testes e certificação.

As especificações técnicas englobam tanto exigências no produto quanto no processo de produção. As exigências no produto especificam características como tamanho, peso, composição, embalagem e outros atributos do produto. Por outro lado, as exigências no processo de produção se referem à forma como é realizada a produção como, por exemplo, os insumos e a tecnologia empregada.

A última categoria apresentada pelos autores é o requerimento de informação que são empregados principalmente na presença de assimetria de informação. Dois principais tipos de requerimentos de informação podem ser distinguidos: a rotulagem obrigatória, imposta por autoridades governamentais para alertar o consumidor de possíveis riscos, e a rotulagem voluntária que são sistemas de certificação gerenciados por indústrias, organizações não governamentais que visam informar ao consumidor características como qualidade do produto, processos de produção que preservam o meio ambiente, produtos orgânicos etc.

A introdução de medidas técnicas nem sempre resulta em ganhos líquidos, seja para o país que introduz a medida, seja para os países impactados pelas medidas. Os desenvolvimentos teóricos a respeito do impacto das medidas técnicas nos fluxos de comércio têm apresentado efeitos ambíguos tanto no bem-estar quanto no comércio. Esses impactos podem ser positivos ou negativos, como será discutido na próxima seção.

\subsection{Efeitos econômicos das medidas técnicas}

Diferente dos instrumentos de política comercial tradicionais como tarifas, cotas, subsídios, entre outros, o impacto das medidas técnicas sobre o fluxo 
de comércio se dá de forma indireta e comumente via aumento de custos de adequação para os exportadores. Além dos custos de produção, em determinadas instâncias, os regulamentos podem impactar também nas decisões de consumo, e indiretamente, o volume das importações realizadas por um determinado país. Portanto, para avaliar esses efeitos, tem sido considerado adequado identificar, primeiramente, o impacto sobre as condições domésticas de oferta e demanda e, consequentemente, as mudanças nas curvas de excesso de demanda interna (ou de demanda por importação) e excesso de oferta interna (ou de oferta de exportação).

A representação gráfica de equilíbrio parcial é útil para visualizar os prováveis deslocamentos nas curvas de oferta e demanda e avaliar possíveis mudanças nos preços, no consumo, na produção e no comércio, advindas da imposição de medidas técnicas. Os efeitos distributivos e líquidos decorrentes da introdução de uma medida técnica também podem ser visualizados via mudanças nos excedentes do produtor e do consumidor.

Para Thilmany e Barret (1997), a principal diferença entre os regulamentos técnicos e outros tipos de barreiras tradicionais é a possibilidade de deslocamentos da demanda com a imposição de regulamentos. Os autores alegam que regulamentos de rotulagem, de segurança e qualidade podem solucionar interesses do consumidor quanto à qualidade e segurança do produto. Portanto, podem, de forma benéfica, resolver problemas de informação imperfeita. A análise de equilíbrio parcial apresentada pelos autores torna evidente que, para regulamentos informativos, não apenas os resultados líquidos de bem-estar são ambíguos, mas o impacto no comércio também.

Na representação esquemática apresentada na Figura 1, os autores consideram um mundo com apenas dois países, sendo o país 1 o importador e o país 2 , o exportador. O mercado internacional (diagrama do meio) de um dado bem $q$ é formado pela interação de excesso de demanda (ED1) e de oferta (EO2) que ocorrem respectivamente nos países importador e exportador.

Figura 1. Efeitos de regulamentos técnicos informativos.

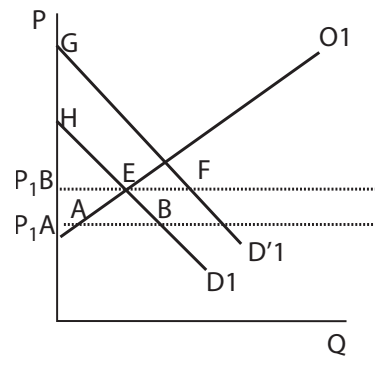

País 1- Importador

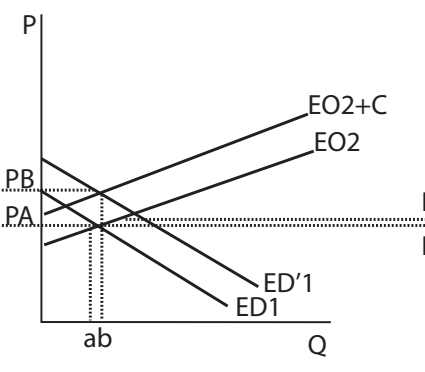

Mercado Internacional

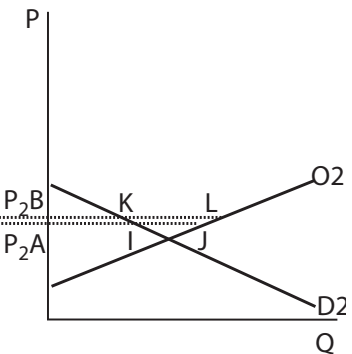

País 2 - Exportador

Fonte: Thilmany e Barret (1997). 
Sob condições de livre comércio, prevaleceria o preço do mercado internacional, $\mathrm{PA}$, em ambos os países. No país 1 , o consumo estaria no ponto $\mathrm{B}$ enquanto a produção estaria no ponto $\mathrm{A}$, o que revela excesso de demanda no montante B - A. No país 2 , o consumo estaria no ponto I, enquanto a produção, no ponto $\mathrm{J}$, o que implica excesso de oferta. $\mathrm{O}$ volume comercializado entre os dois países é igual à $\mathrm{B}-\mathrm{A}=\mathrm{I}-\mathrm{J}=\mathrm{a}$.

Um regulamento imposto pelo país importador como, por exemplo, requisito no processo de produção para garantir a qualidade do produto teria como primeiro impacto a elevação dos custos de exportação para as empresas do país exportador resultantes do processo de adequação à nova exigência. Portanto, a curva de excesso de oferta de exportação do país 2 se desloca de EO2 para $\mathrm{EO} 2+\mathrm{C}$, sendo $\mathrm{C}^{5}$ o custo de adequação por unidade do bem exportado 6 .

Caso o regulamento seja informativo para os consumidores do país importador, haverá também deslocamento da curva de demanda de D1 para D'1 e, consequentemente, deslocamentos na curva de excesso de demanda de ED1 para ED'1. Portanto, o novo ponto de equilíbrio no mercado internacional se dá aos preços $\mathrm{PB}$, superior ao de livre comércio, e a quantidade $\mathrm{b}$ também superior. No que se refere aos preços no mercado internacional, o resultado é certo de elevação dos mesmos, pois esses têm pressões tanto pelo lado da oferta quanto pelo lado da demanda. No entanto, para que o impacto no volume comercializado seja positivo, como mostrado na Figura 1, o regulamento precisa estimular a demanda suficientemente para compensar os aumentos de custos, caso contrário, o impacto no comércio é negativo.

No país importador, os preços se elevam de $\mathrm{P}_{1} \mathrm{~A}$ para $\mathrm{P}_{1} \mathrm{~B}$, e como o regulamento estimula a demanda para compensar os custos, o volume importado aumenta. O bem-estar agregado aumenta somente se a área EFGH (ganho de excedente do consumidor advindo da informação) superar a área $\mathrm{ABE}$ (perda de excedente do consumidor devido aos preços mais altos).

No país exportador, considerando-se que o estímulo na demanda se traduz em estímulo no comércio, então os preços se elevam de $\mathrm{P}_{2} \mathrm{~A}$ para $\mathrm{P}_{2} \mathrm{~B}$; no entanto, o preço no país importador $\mathrm{P}_{1} \mathrm{~B}$ é superior ao preço no mercado exportador $\left(\mathrm{P}_{2} \mathrm{~B}\right)$ devido aos custos que o exportador precisa incorrer para a adequação. $\mathrm{O}$ bem-estar agregado cresce pela área JIKL. Esse resultado tem uma implicação interessante: se o estímulo na demanda compensar os custos de adequação, o efeito no comércio é positivo e as firmas do país exportador podem ficar em uma situação melhor quando o governo do país importador impõe um regulamento.

5 Por conveniência, assume-se que o custo de adequação é constante por unidade vendida.

6 Por simplificação, dentro do país 1, assume-se que não haja deslocamento da curva de oferta com a imposição do regulamento, uma vez que produtores domésticos já estavam adequados a uma norma e o governo a adota como um regulamento. 
Caso a elevação dos custos de adequação superar o deslocamento da demanda, ou no caso em que o regulamento não seja informativo para o consumidor, o efeito no comércio é negativo, e as firmas do país exportador podem ficar em situação pior com a imposição do regulamento.

A imposição de uma medida técnica implica possibilidade de ocorrência de vários pontos de equilíbrio, o que acarreta efeitos ambíguos nos fluxos de comércio e no bem-estar. Para Thilmany e Barret (1997), a informação que a medida pode prover ao consumidor é o elemento-chave na determinação dos seus efeitos.

A despeito das ambiguidades dos impactos dos regulamentos no bem-estar e nos fluxos de comércio, os efeitos de elevação dos custos de adequação para os exportadores são certos e inevitáveis. A adequação às medidas técnicas envolve custos iniciais incorridos para o estabelecimento de novos processos e procedimentos, como redesenho dos produtos, adaptação das unidades produtivas, desenvolvimento de infraestrutura para dar suporte aos procedimentos de avaliação da conformidade, entre outros. Envolve também custos recorrentes, que são aqueles que persistem ao longo do tempo, como por exemplo, o uso de material mais caro para a produção destinada para algum mercado específico, operação em linhas de produção separadas para atender diferentes mercados, contratação de pessoal qualificado para os procedimentos de avaliação da conformidade (MASKUS, WILSON e OTSUKI, 2000; FRAHAN e VANCAUTEREN, 2006; POPPER et al. 2004).

Para Chen, Otsuki e Wilson (2006), os custos de adequação são específicos por empresa e variam conforme suas características, como dotação tecnológica, capacidade de adequação, pessoal qualificado, tamanho, entre outras. Empresas de um mesmo setor podem ter impactos diferentes das medidas técnicas, dependendo de sua capacidade para adequação. $\mathrm{O}$ presente artigo concentrase na avaliação da dificuldade de adequação a diferentes medidas técnicas, que serviria como proxy para os custos de adequação.

\section{Metodologia da pesquisa}

\subsection{O questionário}

O instrumento de coleta de dados foi um questionário estruturado, delineado com base nos trabalhos conduzidos por OCDE (2000) e Wilson e Otsuki (2004). As variáveis utilizadas neste artigo são nove tipos de medidas técnicas (Quadro 1), cuja seleção foi feita com base nos principais trabalhos revisados na literatura (THORNSBURY, 1998; OCDE, 2000; JOSLING, ROBERTS e ORDEN, 2004; WILSON e OTSUKI, 2004; BURNQUIST et al., 2007). Para avaliar o grau de 
636 - Dificuldade de Adequação às Medidas Técnicas: a percepção das empresas exportadoras de alimentos

dificuldade de adequação às nove medidas técnicas, os entrevistados utilizaram a escala de Likert, com variação de 1 a 5.

Quadro 1. Denominação e classificação das variáveis.

\begin{tabular}{|c|c|c|}
\hline Nome & Variável & Classificação \\
\hline \multicolumn{3}{|c|}{ Dificuldade de adequação às medidas técnicas: Qualitativa Ordinal } \\
\hline DPla & Planta e Processo de produção & \multirow{9}{*}{$\begin{array}{l}\text { 1. Nenhuma Dificuldade } \\
\text { 2. Baixa Dificuldade } \\
\text { 3. Média Dificuldade } \\
\text { 4. Alta Dificuldade } \\
\text { 5. Muito Alta Dificuldade }\end{array}$} \\
\hline DConf & Procedimentos de avaliação da conformidade & \\
\hline DPor & Portos de entrada do país comprador & \\
\hline DCar & Características do produto & \\
\hline DSeg & Requisitos de segurança do alimento; & \\
\hline $\mathrm{DAmb}$ & Requisitos ambientais & \\
\hline DRot & Requisitos de rotulagem & \\
\hline $\mathrm{DEmb}$ & Requisitos de embalagem & \\
\hline DRast & Requisitos de rastreabilidade & \\
\hline
\end{tabular}

Fonte: Elaborado pelas autoras.

\subsection{Amostra}

Para a seleção da amostra utilizou-se o catálogo de exportadores brasileiros, disponível no sítio da Confederação Nacional das Indústrias (CNI), cujas empresas responderam, no biênio 2005/2006, por mais de $90 \%$ do valor das exportações brasileiras e $91,2 \%$ do total do número de produtos exportados. $\mathrm{O}$ catálogo totaliza 932 empresas com exportações de alimentos acima de US\$ 100 mil no biênio 2005/06 e contempla empresas de todos os estados brasileiros, de diversos tamanhos e diferentes composições de capital. Foram contatadas, aleatoriamente, 400 empresas, sendo que 117 retornaram o questionário corretamente preenchido, o que constitui a amostra desta pesquisa.

\subsection{Forma de aplicação do questionário}

O primeiro contato com as empresas foi realizado por telefone, buscando conversar com o gerente, diretor ou responsável pela área de exportação para apresentar a pesquisa e coletar o e-mail do informante. Imediatamente após o contato, procedeu-se ao envio do questionário junto a uma carta de apresentação que informava o objetivo da pesquisa, tratava do sigilo da informação e fazia esclarecimentos sobre o envio dos resultados da pesquisa para as empresas participantes.

Após sete dias do envio do questionário, um e-mail de cobrança de reposta foi enviado, e esse procedimento se repetiu durante o período de um mês. A 
coleta dos dados foi realizada durante os meses de agosto, setembro, outubro e novembro de 2007.

\subsection{Procedimentos Estatísticos}

\section{Análise Fatorial e construção dos índices}

A análise fatorial de dados permite reduzir o número original de variáveis, de tal forma que os fatores extraídos possam explicar as variáveis originais. Segundo Johnson e Wichern (2002), o modelo fatorial para a i-ésima variável pode ser expresso algebricamente da seguinte forma:

$$
Y_{i}-\mu_{i}=l_{i 1} F_{1}+l_{i 2} F_{2}+\ldots+l_{i m} F_{i m}+\varepsilon_{i}
$$

em que: $\mu_{i}$ é a média da variável $i ; F_{j}$ representa o j-ésimo fator comum não correlacionado, como média zero e variância unitária; $l_{i j}$ é o fator de carga da i-ésima variável no j-ésimo fator e $\varepsilon_{i}$ é o termo de erro, com média zero, que capta a variação específica em $Y_{i}$ não explicada pelos fatores comuns. $O$ modelo fatorial implica a seguinte estrutura de covariâncias para a i-ésima variável:

$$
\begin{aligned}
& \operatorname{Var}\left(Y_{i}\right)=l_{i 1}^{2}+l_{i 2}^{2}+\ldots+l_{i m}^{2}+\psi_{i} \\
& \operatorname{Cov}\left(Y_{i}, Y_{k}\right)=l_{i l} l_{k 1}+\ldots+l_{i m} l_{k m} \\
& \operatorname{Cov}\left(Y_{i}, F_{j}\right)=l_{i j} \quad i=1,2, \cdots, n \quad \text { e } \quad j=1,2, \cdots, m
\end{aligned}
$$

em que: a porção $\left(l_{i 1}^{2}+l_{i 2}^{2}+\ldots+l_{i m}^{2}\right)$ explicada pelos $m$ fatores comuns é chamada de i-ésima comunalidade e indica a proporção da variância total da variável que é explicada pelo conjunto de fatores comuns e a porção $\Psi_{\imath}$ é chamada de variância específica.

As estimativas das cargas fatoriais podem ser obtidas por vários métodos, porém, nesse trabalho, empregou-se o método mais comum, que são os componentes principais, e utilizou-se a rotação ortogonal Varimax.

Para se testar a adequação do modelo de análise fatorial geralmente utilizam-se a estatística de Kaiser-Meyer-Olkin (KMO) e o teste de esfericidade de Bartlett. O KMO é um indicador que compara a magnitude dos coeficientes de correlação observados com as magnitudes dos coeficientes de correlação parcial, e varia entre 0 e 1 . Pequenos valores de KMO (abaixo de 0,5 ) indicam que o uso da análise fatorial não é adequado. Por sua vez, o teste de esfericidade de Bartlett serve para testar a hipótese nula de que a matriz de correlação é uma 
matriz identidade. Se essa hipótese não for rejeitada, o uso do modelo de análise fatorial deve ser reavaliado (HAIR et al., 2005).

Após a extração dos fatores, foram criados dois índices que sumarizam a informação dada pelos itens que os integram (PESTANA e GAGEIRO, 2005). Considerando o $j$-ésimo fator extraído $\left(F_{j}\right)$, o índice $\left(I_{j}\right)$ é calculado de acordo com a equação (5).

$$
I_{j}=\frac{\sum_{i=1}^{n} Y_{i}}{n}
$$

em que $Y_{i}$ corresponde a cada variável contida em $F_{j}, i=1,2, \cdots, n$ e $n$ é o número total de variáveis contidas em $F_{j}$. Esses índices são médias simples dos valores das variáveis que compõem cada fator e variam de 1 a 5 , sendo que valores próximos de 1 indicam menor dificuldade de adequação às medidas técnicas, e valores próximos de 5 indicam maior dificuldade de adequação.

\section{Teste de Wilcoxon}

O teste de Wilcoxon foi utilizado para testar se as médias dos dois índices encontrados por meio da análise fatorial são estatisticamente diferentes, o que permitiu identificar os tipos de exigências consideradas pelas empresas como as mais difíceis de adequação. A escolha do teste decorreu do fato de a distribuição dos índices não ser normal. Neste caso, o teste de Wilcoxon é uma alternativa não paramétrica ao teste $t$ para amostras emparelhadas. A única pressuposição do teste é que as diferenças entre as duas condições em análises sejam variáveis contínuas com distribuição simétrica. As hipóteses a serem testadas são $H_{0}: E(X)=E(Y) ; H_{a}: E(X) \neq E(Y)$ ou $H_{a}: E(X)>E(Y)$ ou $H_{a}: E(X)<E(Y)$.

De acordo com Pestana e Gageiro (2005), a operacionalização do teste se dá por meio da construção da diferença $D_{i}$ entre as duas condições para cada indivíduo $i$ na amostra. Assim:

$$
\left|D_{i}\right|=\left|Y_{i}-X_{i}\right|
$$

em que $Y_{i}$ é uma condição para o indivíduo $i$ e $X_{i}$ é uma outra condição para o mesmo indivíduo $i$. A estatística do teste quando existem empates é dada por:

$$
T=\frac{W^{+}-W^{-}}{\sqrt{\sum_{i=1}^{n} R_{i}^{2}}}
$$

em que $W^{+}$é a soma das ordens que correspondem a diferenças $D_{i}$ positivas; $W$ é a soma das ordens que correspondem a diferenças $D_{i}$ negativas e $R_{i}$ é a ordem atribuída a $\left|D_{i}\right|$. A estatística do teste quando não existem empates é dada por: 


$$
T=\frac{W^{+}-\frac{n(n+1)}{4}}{\sqrt{n(n+1)(2 n+1) / 24}}
$$

Havendo empates, ou para grandes amostras, a distribuição de $T$ tende à distribuição normal.

\section{Análise dos resultados}

\subsection{Caracterização das empresas da amostra}

Quanto à origem do capital controlador, os dados evidenciam a predominância de empresas de capital nacional na amostra, representando 85\% do total das empresas respondentes. Esse valor é consistente com a indústria de alimentos no Brasil, onde há predomínio de empresas cujo controle acionário é nacional.

No que se refere ao tamanho das empresas, $26 \%$ são micro e pequenas empresas (até 99 funcionários), 36\% são médias empresas (100 a 499 funcionários) e 38\% são grandes (acima de 500 funcionários).

Em termos de distribuição das empresas quanto ao tipo de alimento exportado, observou-se que $21,5 \%$ exportam "frutas e vegetais frescos e processados" e o segundo tipo com maior representatividade é "açúcares, produtos de confeitaria e cacau", com 17,1\%. "Carnes e peixes frescos e processados", com 14,5\%, aparecem na terceira posição (Figura 2).

Figura 2. Participação das empresas por tipo de alimento exportado.

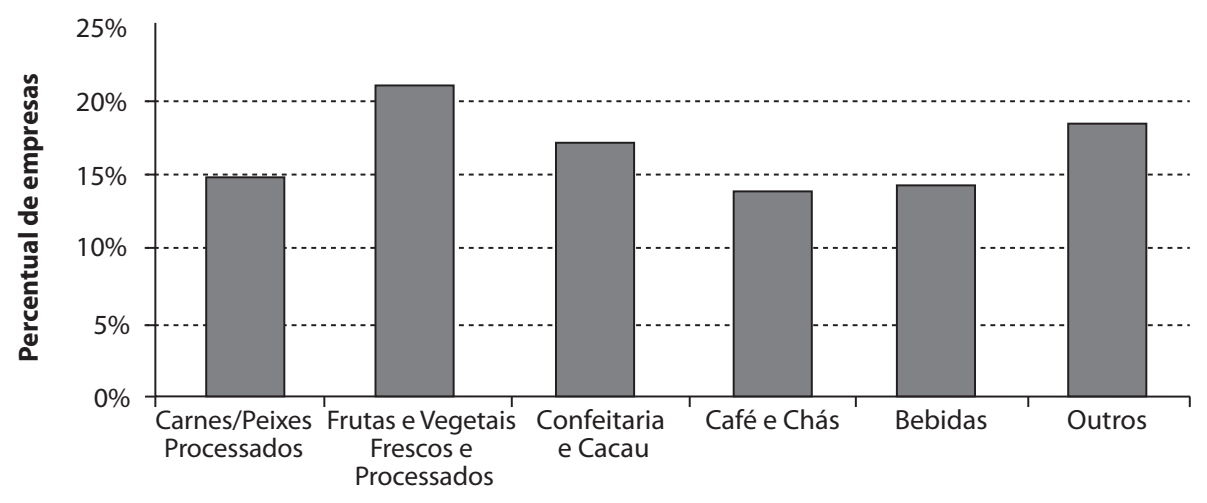

Categorias de Produtos

Fonte: Resultados da pesquisa. 
640 - Dificuldade de Adequação às Medidas Técnicas:

a percepção das empresas exportadoras de alimentos

\subsection{Construção dos índices por meio da análise fatorial}

Os testes mostraram que os dados são passíveis de serem analisados por meio da técnica de análise fatorial. A matriz de correlação mostrou correlações estatisticamente significativas entre as variáveis. $O$ teste de esfericidade de Bartlett foi significativo a $1 \%$, rejeitando a hipótese nula de que a matriz de correlação é uma matriz identidade. O teste de Kaiser-Meyer-Olkin (KMO) apresentou valor de 0,809, que, segundo Pestana e Gageiro (2005), permite classificar a adequação da amostra de dados à análise fatorial como boa.

O critério para determinação do número de fatores foi a extração daqueles cujas raízes características são maiores que a unidade. Dois fatores foram extraídos e esses são responsáveis por aproximadamente $60 \%$ da variabilidade total das variáveis (Tabela 1 ).

Tabela 1. Raízes características da matriz de correlação, proporção e proporção acumulada da variância explicada pelos fatores.

\begin{tabular}{cccc}
\hline Fatores & Raiz Característica & \% da Variância & \% Acumulada \\
\hline 1 & 4,119 & 45,772 & 45,772 \\
2 & 1,242 & 13,798 & 59,570 \\
3 & 0,871 & 9,677 & 69,247 \\
4 & 0,690 & 7,671 & 76,918 \\
5 & 0,592 & 6,575 & 83,493 \\
6 & 0,478 & 5,307 & 88,800 \\
7 & 0,441 & 4,898 & 93,697 \\
8 & 0,338 & 3,758 & 97,456 \\
9 & 0,229 & 2,544 & 100,000 \\
\hline
\end{tabular}

Fonte: Resultados da pesquisa.

A Tabela 2 apresenta a distribuição das variáveis originais nos respectivos fatores extraídos (chamados $\mathrm{DIF}_{1}$ e $\mathrm{DIF}_{2}$ ), as comunalidades e as cargas fatoriais. Como as variáveis utilizadas no modelo fatorial foram medidas por meio de uma escala de Likert, utilizou-se o Alpha de Cronbach para verificar a consistência interna dos fatores. O teste verifica se as respostas diferem não porque a questão é confusa ou leve a diferentes interpretações, mas porque os respondentes têm diversas opiniões. $O$ resultado para o $F_{1}$ foi de 0,792 e para $F_{2}$ foi 0,771 , o que indica razoável consistência interna.

O primeiro fator $\left(\mathrm{DIF}_{1}\right)$ explica 31,41\% da variabilidade total e está mais forte e positivamente correlacionado com as variáveis: Dificuldade de adequação da planta e do processo de produção (DPla); Dificuldade de adequação a requisitos de segurança do alimento (DSeg); Dificuldade nos procedimentos de avaliação da conformidade (DConf); Dificuldade de adequação a requisitos 
ambientais (DAmb) e Dificuldade de adequação relacionada às características do produto (DCar).

Tabela 2. Cargas fatoriais, comunalidades e percentagem da variância total correspondente a cada fator, após a rotação.

\begin{tabular}{lccc}
\hline \multirow{2}{*}{\multicolumn{1}{c}{ Variáveis }} & \multicolumn{2}{c}{ Carga Fatorial } & \multirow{2}{*}{ Comunalidade } \\
\cline { 2 - 3 } & $D I F_{1}$ & $D I F_{2}$ & \\
\hline DPla - Planta e processo de produção & 0,819 & 0,127 & 0,686 \\
DSeg - Requisitos de segurança do alimento & 0,782 & $-0,016$ & 0,612 \\
DConf - Procedimentos de avaliação da conformidade & 0,656 & 0,251 & 0,494 \\
DAmb - Requisitos ambientais & 0,597 & 0,474 & 0,581 \\
DCar - Características do produto & 0,578 & 0,378 & 0,477 \\
DRast - Requisitos de rastreabilidade & 0,512 & 0,508 & 0,520 \\
DRot - Requisitos de rotulagem & 0,033 & 0,842 & 0,710 \\
DEmb - Requisitos de embalagem & 0,377 & 0,751 & 0,706 \\
DPor - Portos de entrada do país comprador & 0,137 & 0,746 & 0,575 \\
Percentagem da Variância após rotação & 31,412 & 28,157 & \\
\hline
\end{tabular}

Fonte: Resultados da pesquisa.

Em geral, as exigências nas plantas de produção ou no processo são impostas exatamente para se alcançar um nível de segurança alimentar aceitável e atingir algumas características dos produtos. Portanto, essas variáveis são correlacionadas. Um exemplo, ilustrativo pode ser o caso do mamão papaya, em que várias exigências no processo de produção visam assegurar a sua não contaminação pela mosca-da-fruta. Por outro lado, os procedimentos de avaliação da conformidade podem ser aplicados tanto nas plantas e processos de produção quanto nos produtos, para verificar se requisitos estabelecidos foram atendidos. Os requisitos ambientais podem se manifestar em exigências de rotulagem ambiental dos produtos, no entanto, os rótulos expressam uma adequação da empresa em termos do processo de produção ou mesmo do produto, de forma a reduzir os impactos no meio ambiente.

No segundo fator $\left(\mathrm{DIF}_{2}\right)$ predominam as exigências que têm como principal objetivo prover informações do setor produtivo para os consumidores. Esse explica $28,15 \%$ da variabilidade total e está mais fortemente correlacionado com: Dificuldade de adequação a requisitos de rotulagem (DRot); Dificuldade de adequação a requisitos de embalagem (DEmb); Dificuldade nos portos de entrada do país comprador (DPor) e Dificuldade de adequação a requisitos de rastreabilidade (DRast).

Percebe-se que a carga fatorial da variável (DRast) está dividida entre os dois fatores, ou seja, ela poderia ser considerada tanto na interpretação 
do $\mathrm{DIF}_{1}$ quanto de $\mathrm{DIF}_{2}$. Apesar da análise das cargas fatoriais indicarem que a variável está um pouco mais correlacionada com o DIF ${ }_{1}$, optou-se por considerá-la no segundo fator, uma vez que o propósito da rastreabilidade é garantir que a origem e a localização do produto possam ser identificadas de forma precisa e eficiente na cadeia de produção. Dessa forma, o objetivo é prover informações suficientes para localizar o produto em todas as fases da produção, do processamento e da distribuição, e permitir o conhecimento do conteúdo do produto como ele foi produzido e cada local que esse passou. Em outras palavras, a rastreabilidade é um conjunto de procedimentos que permite que a informação seja disponibilizada às autoridades competentes e aos consumidores.

Como apresentado na equação (5), o primeiro índice foi calculado como uma média simples do valor assumido pelas variáveis que compõem o $\mathrm{DIF}_{1}$, portanto, é composto pela dificuldade de adequação às exigências relacionadas à planta e ao processo (DPla), requisitos de segurança alimentar (DSeg), procedimentos de avaliação da conformidade do produto (DConf), característica do produto (DCar) e requisitos de meio ambiente (DAmb). Esse índice engloba normas e regulamentos de produtos (como especificação de ingredientes e restrição de aditivos, especificações de cor, peso, aroma, entre outros) e requisitos nos processos (como por exemplo, o System Approach que é especificado para reduzir progressivamente a probabilidade de infestação de pragas que podem ser importadas junto ao alimento). Seguindo Roberts, Josling e Orden (2004), o índice pode ser interpretado como uma medida do grau de dificuldade de adequação às especificações técnicas, tanto no processo quanto no produto; portanto, foi denominado Índice de Especificação Técnica (IET).

De forma análoga, realizou-se o cálculo do segundo índice derivado de $\mathrm{DIF}_{2}$ e composto pela dificuldade de adequação aos requisitos de embalagem (DEmb), rotulagem (DRot), rastreabilidade (DRast) e dificuldade nos portos de entrada (DPor). Esse índice envolve medidas cujo objetivo é prover informações aos consumidores para reduzir o risco associado ao produto (se for uma medida obrigatória) ou mesmo assegurar ao consumidor características de qualidade ou algum outro atributo (se for medida voluntária); portanto, foi denominado Índice de Requerimentos de Informação (IRI).

\subsection{Comparação dos índices de dificuldade de adequação}

Observa-se, pela Tabela 3, que a média do IET é levemente superior à do IRI, o que pode indicar que as empresas exportadoras de alimentos têm, em média, mais dificuldade para se adequar aos requisitos na fabricação do produto ou no processo produtivo relativamente aos requisitos relacionados à informação e embalagem. 
Tabela 3. Estatísticas descritivas dos índices.

\begin{tabular}{ccc}
\hline Índices & Média & Desvio padrão \\
\hline IET & 2,55 & 0,772 \\
IRI & 2,36 & 0,779 \\
\hline
\end{tabular}

Fonte: Resultados da pesquisa.

Para verificar se as médias dos dois índices são estatisticamente diferentes, o teste de Wilcoxon para diferenças de médias foi aplicado e o resultado está na Tabela 4.

Tabela 4. Resultado do teste de Wilcoxon.

\begin{tabular}{cc}
\hline Estatísticas & IRI - IET \\
\hline$Z$ & $-3,031$ \\
P-Valor & 0,002 \\
\hline
\end{tabular}

Fonte: Resultados da pesquisa.

O resultado do teste de Wilcoxon revela que a média de dificuldade atribuída ao Índice de Especificação Técnica (IET) difere, ao nível de significância de 1\%, da média atribuída ao Índice de Requerimentos de Informação (IRI). O sinal da estatística $Z$ do teste permite concluir que as empresas amostradas percebem dificuldades maiores para se adequar aos requisitos relacionados ao processo de produção e ao produto relativamente aos requisitos relacionados à provisão de informação.

Roberts, Josling e Orden (2004) argumentam que os requisitos de informação são percebidos como uma forma menos onerosa de regulamentos, embora quando os requerimentos variam significativamente entre os mercados, os exportadores podem incorrer em custos para produzir diferentes rótulos, além de custos substanciais de manutenção de estoques para cada mercado. Os resultados encontrados confirmam os argumentos dos autores, ou seja, os tipos de exigências que impõem maiores dificuldades de adequação para as empresas exportadoras de alimentos no Brasil são as especificações técnicas referentes a processos e produtos.

\section{Conclusões e implicações}

A pesquisa mostra que é possível identificar e mensurar o grau de dificuldade de adequação às medidas técnicas e expressá-lo por meio dos dois índices: IET e IRI. A construção dos índices de dificuldade constitui a maior contribuição empírica desta pesquisa, pois os mesmos podem ser disponibilizados e assim utilizados em análises subsequentes por pesquisadores da área. Ademais, 
a possibilidade de evolução desses índices, tanto no tempo (calculado para diferentes anos), quanto no conteúdo (como inclusão de variáveis), permitiria estudos importantes como a avaliação de seus impactos nos fluxos de comércio por meio de dados em painel.

Outra conclusão importante é que, para as empresas amostradas, a média do IET é superior à do IRI, o que evidencia maior dificuldade de adequação às especificações técnicas (adequação da planta e do processo de produção, conformidade, segurança do alimento, características do produto e meio ambiente) relativamente às exigências de requerimento de informação (como rotulagem, embalagem, rastreabilidade e portos de entrada). De fato, os investimentos necessários para a adequação do processo de produção são inegavelmente superiores aos necessários para se adequar uma embalagem ou um rótulo, tendo em vista que envolve balanceamento da capacidade da linha de produção, otimização do arranjo físico e/ou adequação do projeto de fábrica.

No entanto, tem sido observada uma tendência crescente de imposição de medidas técnicas que envolvem questões de qualidade, exigências ambientais e requisitos nos processos de produção, especialmente por parte dos países desenvolvidos, cujos consumidores são mais exigentes quanto à segurança alimentar, questões ambientais de qualidade, entre outras.

A maior dificuldade de adequação às especificações técnicas aliada à crescente imposição desse tipo de medidas pelos países compradores evidencia a necessidade de incentivos públicos, bem como ações do setor privado no sentido de se reduzirem os custos de adequação às medidas técnicas. Como ações públicas, destacam-se maiores investimentos em infraestrutura laboratorial, treinamento e desenvolvimento de habilidades e competências nos sistemas de gestão de qualidade e criação de linhas de crédito específicas para o financiamento do processo de certificação para pequenas empresas. Além disso, a participação em negociações internacionais relacionadas às exigências técnicas e elaboração de regulamentos domésticos alinhados aos regulamentos aceitos internacionalmente contribuiria para facilitar o processo de adequação e promover as exportações de alimentos no Brasil.

No que tange às empresas, essas precisam estar atentas à incorporação de métodos de produção mais seguros, implantação de sistemas de qualidade e gerenciamento das práticas ambientais para que possam cumprir mais facilmente as demandas dos países compradores.

Para pesquisas futuras, sugere-se a realização de estudos que busquem investigar quais são as dificuldades enfrentadas pelas empresas para se adequarem às especificações técnicas, visto que essas se apresentaram como mais restritivas. Conhecer os obstáculos no processo de ajustamento às medidas é essencial para propor ações tanto privadas quanto públicas. 


\section{Referências Bibliográficas}

BURNQUIST, H.L. et. al. Análise de evidências sobre a importância de barreiras técnicas à exportação de empresas brasileiras. Revista de Economia Aplicada, Ribeirão Preto, v. 11, no 2, 2007. p. 209-229.

CHEN, M. X; OTSUKI, T.; WILSON, J. S. Do standards matter for export success? World Bank Policy Research, Washington, Working Paper n. 3809, 2006. 26 p. Disponível em: http://www-wds.worldbank.org/external/default/ WDSContentServer/IW3P/IB/2006/01/18/000016406_20060118152026/Rendered/ PDF/wps3809.pdf. Acesso em: 05 jan. 2007.

FARIA, R.N. Efeitos da imposição de barreiras não-tarifárias nas exportações brasileiras de mamão. 2004. 149 p. Dissertação (Mestrado em Economia Aplicada) Universidade Federal de Viçosa, Viçosa, 2004.

FARIA, R. N; BURNQUIST, H. L. Análise do Grau de Restritividade de Exigências Técnicas às Exportações Brasileiras. Revista de Economia e Agronegócio, v. 4, no4, 2006. p. 411-430.

FRAHAN, B. H; VANCAUTEREN, M. Harmonisation of food regulations and trade in the Single Market: evidence from disaggregated data. European Review of Agricultural Economics, v. 33, no3, set., 2006. p. 337-360.

HAIR, J. F. JR; ANDERSON, R. E; TATHAM, R. L; BLACK, W. C. Análise Multivariada de dados. Trad. Adonai Schulp Sant'Anna e Anselmo Chaves Neto. 5ee Porto Alegre: Bookman, 2005. 593 p.

JOHNSON R. A; WICHERN D. W. Applied multivariate statistical analysis, 5e․ New Jersey: Prentice hall, 2002, 767 p.

JOSLING, T; ROBERTS, D; ORDEN, D. Food Regulations and Trade: Toward a Safe and Open Global System. Washington: Institute for International Economics, 2004. 260p.

JUNQUEIRA, B. A. Identificação e análise de barreiras não-tarifárias sobre as exportações brasileiras de carne bovina. 2006. 138 p. Dissertação (Mestrado em Economia Aplicada) - Universidade Federal de Viçosa, Viçosa, 2006.

MASKUS, K. E.; WILSON, J. S; OTSUKI, T. Quantifying the impact of technical barriers to trade. A framework for analysis. World Bank Policy Research, Washington, Working Paper n. 2512, dez, 2000. 56 p.

MIRANDA, S.H.G. Quantificação dos efeitos das barreiras não-tarifárias sobre as exportações brasileiras de carne bovina. 2001. 233 p. Tese (Doutorado em Economia 
646 - Dificuldade de Adequação às Medidas Técnicas: a percepção das empresas exportadoras de alimentos

Aplicada) - Escola Superior de Agricultura "Luiz de Queiroz", Universidade de São Paulo, Piracicaba, 2001.

ORGANIZAÇÃO MUNDIAL DO COMÉRCIO - OMC. World trade report 2005. Disponível em http://www.wto.org/english/news_e/pres05_e/pr411_e.htm. Acesso em: 12 set. 2006.

OCDE. An assessment of the costs for international trade in meeting regulatory requirements. Working Party of the Trade Committee, Paris, 2000, 118 p. Disponível em http://www.olis.oecd.org/olis/1999doc.nsf/LinkTo/ NT000029FE/\$FILE/00073222.PDF . Acesso em: 8 set. 2006.

PESTANA, M. H; GAGEIRO, J. N. Análise de dados para ciências sociais - a complementaridade do SPSS, 4 ed. Lisboa: Edições Sílabo, 2005, 690 p.

POPPER, S. W.; GREENFIELD, V.; CRANE,K.;MALIK, R. Measuring economic effects technical barriers to trade on U.S exporters. National Institute of Standards and Technology (2004), 191p. Disponível em http://www.google.com/search?hl=pt$\mathrm{BR} \& \mathrm{l} \mathrm{r}=\& \mathrm{q}=\% 22$ Popper $\% 22+\% 22$ Measuring + Economic + Effects $\% 22$. Acesso em: 13 nov. 2006.

ROBERTS, D.; ORDEN, D.; JOSLING, T. A framework for analysing technical barriers to agricultural markets. Thechnical Bulletin, n. 1876, Market and Trade Economics Division, US. Department of Agriculture, 1999.

SOUZA, M.J.P;; BURNQUIST, H.L. Impactos das exigências técnicas impostas as exportações brasileiras de melão. In: CONGRESSO DA SOCIEDADE BRASILEIRA DE ECONOMIA E SOCIOLOGIA RURAL, 45., 2007, Londrina. Anais... Brasília: SOBER, 2007. p. 223-244.

THILMANY, D.D.; BARRET, C.B. Regulatory barriers in an integrating world food market. Review of Agricultural Economics, Milwaukee, v. 19, no 1, 1997. p. 91-107.

THORNSBURY, S. Technical regulations as barriers to agricultural trade. 1998. 192 p. Dissertation (Doctor of Philosophy in Agricultural and Applied Economics) Faculty of Virginia Polytechnic Institute and State University, Blacksburg, 1998.

WILSON, J. S; OTSUKI, T. Standards and Technical Regulations and Firms in Developing Countries: New Evidence from A World Bank Technical Barriers to Trade Survey. Washington: (Preliminary Draft) The World Bank, 2004. 55p. Disponível em: http://siteresources.worldbank.org/INTRANETTRADE/ Resources/Topics/Services/TBT_Data_Description.pdf. Acesso em: 05 jan. 2006. 